\title{
Implementation of tidal parameterization in the Weather Research and Forecasting (WRF) model
}

\author{
Young-Hee Lee ${ }^{1, *}$, Kwang-Deuk Ahn ${ }^{2}$, Yong Hee Lee ${ }^{2}$, and Hyunmin Eom ${ }^{3}$ \\ ${ }^{1}$ Department of Astronomy and Atmospheric Sciences, Kyungpook National University, Daegu, Korea \\ ${ }^{2}$ Numerical Data Application Division, Numerical Modeling Center, Korea Meteorological Administration, Seoul, Korea \\ ${ }^{3}$ Marine Meteorology Division, Korea Meteorological Administration, Seoul, Korea
}

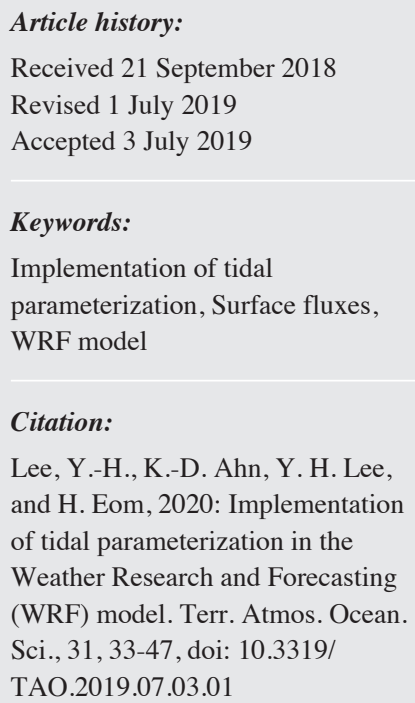

\begin{abstract}
In this study, the Noah land surface model with a tidal parameterization was implemented in the WRF model. Newly added inputs included gridded tidal data that indicated the presence of a tidal flat, and a time varying water layer thickness over the tidal flat. Two simulations were performed in an online mode, namely, a simulation without tidal effects (CNTL) and simulation with tidal effects (TIDE). A comparison between the simulations and observations at flux tower showed that the surface heat and momentum fluxes were well reproduced in the TIDE simulation both in the magnitude and variation. In spite of better surface flux simulations, the air temperatures were slightly better simulated in the TIDE simulation than in the CNTL simulation during nighttime only. The $10 \mathrm{~m}$ wind speed was slightly overestimated in the TIDE compared to the CNTL simulation. The mean differences in the field variables between the TIDE and CNTL simulations were examined for four cases during the simulation period (inundation and exposed conditions at night and inundation and exposed conditions during the day). Tidal grids were classified into two groups depending on the land use type in the CNTL simulation as either the land to tide (LT) group or the water to tide (WT) group. The magnitude of the $2 \mathrm{~m}$ air temperature difference between the two simulations was generally larger on LT group than on WT group. During the day, both the $2 \mathrm{~m}$ air temperature and the planetary boundary layer height (PBLH) decreased under inundation conditions over LT group. The impact of the tidal flat on $10 \mathrm{~m}$ wind and PBLH extended inland beyond the tidal flats during the daytime inundation period.
\end{abstract}

\section{INTRODUCTION}

Many urban cities are located in coastal areas or downwind of the coast; hence, realistic simulations of coastal meteorology are important for forecasting rapidly developing convective systems and predicting air quality (Lu and Turco 1995) over coastal areas. Some convective cells develop near the coast within a few hours and yield heavy rainfall in the downwind area. Heat and moisture are provided to the convective cells through surface fluxes, and the extent of the vertical mixing of air pollutants also depends on the surface heat fluxes (Stull 1988). Realistic simulations of surface fluxes in coastal regions also influences the intensity of sea breezes and the movement of sea breeze fronts (e.g.,

\footnotetext{
* Corresponding author

E-mail:young@knu.ac.kr
}

Crosman and Horel 2010).

Segments of coastal areas are covered by tidal flats that are alternately exposed and inundated by low and high tides, respectively. This leads to significant temporal changes in the surface fluxes over the tidal flats (Harrison 1985). The Yellow Sea is an ocean with large sea level differences between the tidal ebbs and flows. In low resolution models, tidal flats are not usually resolved. However, as the spatial resolution of a model increases with increasing computational speed (Hong and Dudhia 2012), some grid points near the shorelines can correspond to tidal flats. For better simulations of the surface fluxes on tidal flats, a parameterization for tidal flats has been developed and validated against eddy covariance data obtained at a single tower over a tidal flat in offline mode (Lee et al. 2016). The parameterization is 
based on the energy budget of a water layer with varying thickness above the soil.

The impacts of land parameterization and land use data on meteorological fields in the lower atmosphere have been investigated using three-dimensional (3-D) numerical models in many studies (Otte et al. 2004; De Meij and Vinuesa 2014). Otte et al. (2004) implemented an urban canopy parameterization in the fifth-generation Pennsylvania State University-National Center for Atmospheric Research Mesoscale Model (MM5) and showed that the urban canopy parameterization produces profiles for the wind speed, friction velocity, turbulent kinetic energy, and potential temperatures more consistently with the observations in urban areas than simulations that use the roughness approach. De Meij and Vinuesa (2014) examined the impact of high resolution topography and land use data on meteorological fields using the Weather Research and Forecasting (WRF) model and showed that changes in land use influence wind speed and air temperatures near the surface. To examine how significantly surface forcing of tidal flats influences meteorological fields, incorporation of a tidal parameterization into a 3-D model is required. Kessler et al. (1985) attempted to simulate the effect of tidal flat on sea-breeze development using idealized two-dimensional numerical simulation. However, tidal effects have not been considered in realistic 3-D numerical models.

In this study, we implemented a tidal parameterization in the WRF model and evaluated the implementation of tidal parameterization in the WRF using observed data over a tidal flat. We then examined the impact of the tidal parameterization on the simulated meteorological fields.

\section{MATERIAL AND METHOD}

\subsection{Model Setup and Data}

In this study, the fully compressible non-hydrostatic WRF model version 3.7 with multiple nesting capabilities was used (Skamarock et al. 2008). The domain configuration consisted of four nested domains with two-way interactions. The horizontal grid spacings for the four domains were $27 \mathrm{~km}(80 \times 80), 9 \mathrm{~km}(64 \times 64), 3 \mathrm{~km}(70 \times 70)$, and $1 \mathrm{~km}(82 \times 82)$. Domain 4 covered the western coast and Seoul metropolitan area. The vertical grids contained 45 full sigma levels from the surface to $50 \mathrm{hPa}$. The lowest half sigma level was about $12.5 \mathrm{~m}$.

Figure 1a shows the WRF model domain. The simulations were initialized at 1200 UTC 5 September 2014 and lasted $78 \mathrm{~h}$. The National Centers for Environmental Prediction (NCEP) final (FNL) operational model global tropospheric analyses data were used for the initial and boundary conditions. The NCEP FNL analyses are available on a $1.0^{\circ}$ $\times 1.0^{\circ}$ grid every $6 \mathrm{~h}$. For the sea surface temperature (SST), we used the NCEP real-time SST archives with a $0.083^{\circ}$ horizontal resolution that are commonly used in WRF simulations. The SST data are provided by the NCEP daily and can be downloaded on the web (ftp://polar.ncep.noaa.gov/ pub/history/sst/rtg_high_res/). The SST data of 6 September 2014 were used during simulation period. The land cover data used were the Korean Peninsula 30-arc second data (Park and Suh 2015) and the Seoul Metropolitan area 3-arc second data (NIMR 2014).

The parameterizations chosen for this study include the Dudhia simple cloud-interactive shortwave radiation (a)

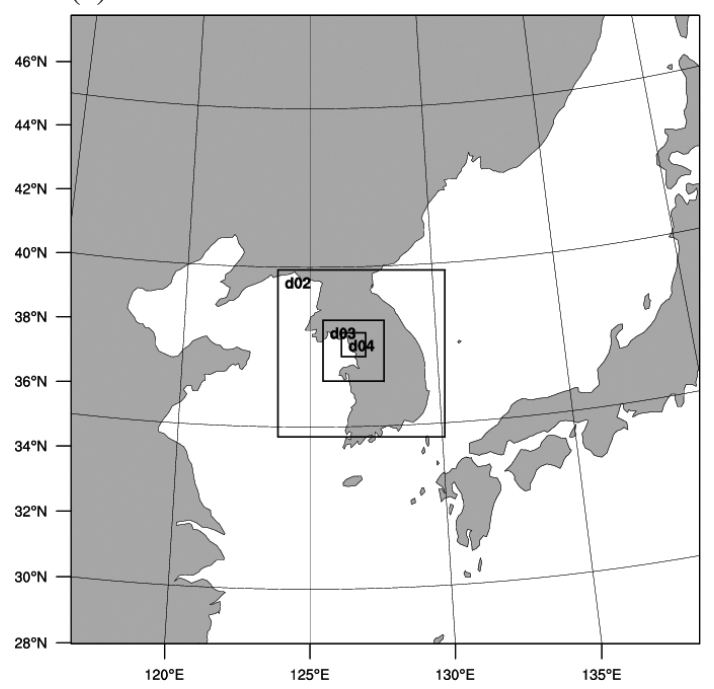

(b)

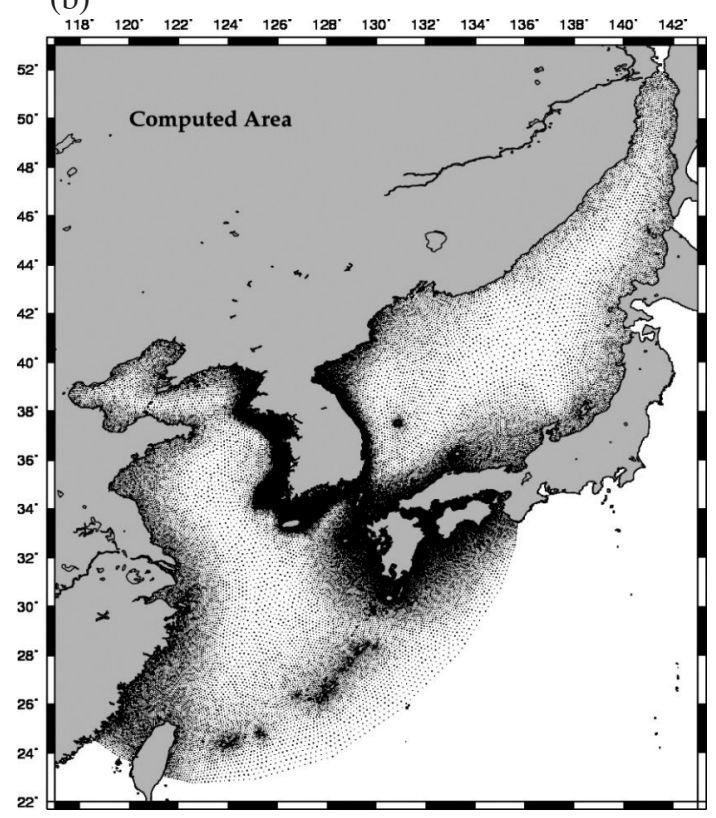

Fig. 1. (a) WRF model domain configuration and the (b) FVCOM model domain 
scheme (Dudhia 1989), Rapid Radiative Transfer Model (RRTM) longwave radiation scheme (Mlawer et al. 1997), YSU planetary boundary layer (PBL) scheme (Hong et al. 2006), revised MM5 Monin-Obukhov scheme, and the Goddard microphysics scheme (Tao et al. 1989). In order to examine the tidal effects on the simulation, two land surface schemes were used, namely, the Noah land surface scheme (Chen and Dudhia 2001), and the Noah land surface scheme with tidal parameterization (Lee et al. 2016). The KainFritsch cumulus parametrization scheme (Kain and Fritsch 1993) was used for the three outer domains.

The modelled results were compared with the eddy covariance data as well as the air temperature and wind speed data measured at the observation site on selected days. The observation site is located in the tidal flats off the western coast of South Korea $\left(126^{\circ} 25^{\prime} \mathrm{E}, 37^{\circ} 26^{\prime} \mathrm{N}\right)$. Figure 2 shows a satellite photo of the flux observation site. Due to difficulty of installing a tower on the tidal flat, a tower was installed at the eastern boundary of the tidal flat and hence it provides good fetches of the tidal flat during westerly wind conditions, but not during easterly wind conditions. To the east of the tower, there are farmlands and forests. The wind velocity components $u, v, w$, and the air temperature $T$ were measured using a 3-D sonic anemometer (CSAT3, Campbell Inc., USA), and the water vapor $q$ was measured $10 \mathrm{~m}$ above the ground using a gas analyzer (EC150, Campbell Sci., USA). The sampling rate for the turbulence measurements was $10 \mathrm{~Hz}$. The net radiation was measured using the CNR4 net radiometer (Campbell Sci., USA). The water layer thickness was measured using a sonic ranging sensor (SR50A, Campbell Sci., USA) that measures the distance from the sensor height to the surface. All energy fluxes were calculated at $30 \mathrm{~min}$ intervals. The data processing is described in Lee et al. (2016). The measurement period was from 12 August to 26 September 2014. To compare the modelled results with the observations, we selected three days with clear daytime sky conditions and westerly winds.

\subsection{Implementation of Tidal Parameterization into WRF Model}

The tidal parameterization was based on the water layer energy budget with changing thickness above the soil. Details of the parameterization are described in Lee et al. (2016). Here, we briefly describe the features related to implementing the tidal parameterization into the WRF model. To consider alternate exposures and inundations over a tidal flat, different surface energy budget equations were employed during the inundation and exposed periods on the tidal grid, respectively. During inundation, the surface energy budget with a heat storage term for the water layer is given by

$R_{n}-G-H-L_{v} E_{p}=S$

where $R_{n}$ is the net radiation, $G$ is the ground heat flux into the soil, $H$ is the sensible heat, $E_{p}$ is the potential evaporation from the water surface, $L_{v}$ is the latent heat of vaporization, and $S$ is the water layer heat storage term.

The heat storage term for the water layer is calculated as

$S=\rho_{w} C_{p} \frac{\Delta T_{w}}{\Delta t} d_{w}$

where $\rho_{w}$ is the density of water, $C_{p}$ is the heat capacity of water, $\Delta T_{w}$ is the water layer temperature change, $\Delta t$ is the time step, and $d_{w}$ is the water layer thickness.

In the coupled mode, the water layer temperature change is very small due to the small time step. Therefore,

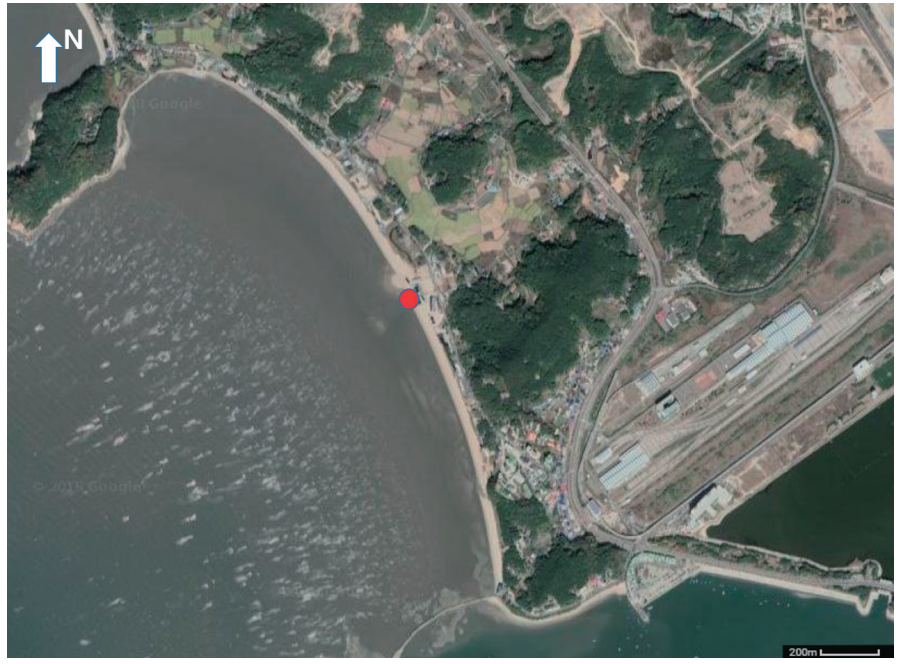

Fig. 2. The flux observation site landscape (http//www.google.com/map). The red circle indicates the location of the flux tower. 
double precision was used for the water temperature and related variables to calculate the water layer heat storage term. During the exposed soil condition, the surface energy balance equation for the bare ground without the heat storage term was employed.

On the tidal flats, the aerodynamic roughness length was given as $0.01 \mathrm{~m}$ during the exposed soil conditions, while in the presence of the water layer, the aerodynamic roughness length was calculated as Charnock's (1955) expression plus a smooth flow limit, following Smith (1988)

$z_{0 m}=a \frac{u_{*}^{2}}{g}+b \frac{v}{u_{*}}$

where $v$ is the kinematic viscosity, $g$ is the gravitational acceleration, and the constants $a$ and $b$ are 0.0185 and 0.11 , respectively.

The water heat content was influenced by the horizontal heat advection due to movement as well as the surface energy balance. The SST was used to consider the horizontal heat advection given by

$\theta_{1}=\left[\theta_{\text {lold }} d_{w o l d}+\operatorname{SST}\left(\Delta d_{w}\right)\right] / d_{w}$ for $\Delta d_{w}>0$

$\theta_{1}=\theta_{\text {lold }}$

for $\Delta d_{w} \leq 0$

where $\theta_{\text {lold }}$ and $d_{\text {wold }}$ are the water temperature and water thickness at the previous time step, respectively, and $\Delta d_{w}$ is the increase in water thickness from the previous time step. The water thickness data were provided at $30 \mathrm{~min}$ intervals and hence the horizontal heat advection was considered at 30 min intervals.

To implement a tidal parameterization into the WRF model, two additional gridded inputs are required: tidal data that indicates the tidal flat presence on the grid and the water layer thickness of the tidal grid. To acquire the required inputs for the model domain, we used the output from the finite-volume coastal ocean model (FVCOM). The FVCOM is an unstructured grid, finite-volume, 3-D primitive equation ocean model (Chen et al. 2003). Figure 1b shows the FVCOM model domain where the horizontal grid spacing is about $100 \mathrm{~m}$ around the coast and increases in the interior and near the open boundary. The ocean model was initialized with a cold start and the spin up time was three days. In the open boundary, the four largest tidal constituents in the Gyeonggi Bay were applied. The ocean model was run in a barotropic mode. The model outputs used in this study were sea surface elevation and the wet and dry indexes at 30 min intervals. When the grid in the FVCOM experienced an alternate exposure and inundation during the simulation period, we classified the grid as a tidal grid in the FVCOM. Many FVCOM grid points were included in each WRF grid.
When a grid was more than half covered by tide, the grid was classified as a tidal grid in the WRF.

The time varying thickness of the water layer on the tidal grid was calculated as

$d_{w}=h_{t}-h_{\min }$

where $h_{t}$ is the sea surface elevation and $h_{\min }$ is the minimum surface elevation at the same point.

The minimum surface elevation was defined as the surface elevation when the grid is exposed.

\section{RESULTS}

Two simulations were performed: a control simulation without the tidal effects (CNTL) and a simulation with the tidal effects (TIDE). We focused on the simulation results of domain 4 with a $1 \mathrm{~km}$ resolution where the tidal flats were resolved. The nearest grid to the tower site was not classified as a TIDE grid because the site is located at the boundary of the tidal flat and current method does not detect all small-scale tidal flats. For comparison with the observations, we added an additional tidal grid at the tower site in the TIDE simulation. At the additional tidal grid, the water layer thickness was not calculated and hence the observed water layer thickness was used.

\subsection{Tides and Water Layer Thickness}

Figure 3a shows the horizontal distribution of the tidal grid computed using the method described in section 2.2. The tidal grids were located near the shoreline, indicating that the current method reasonably detected the tidal flat. There were a total of 287 tidal grids including an additional tidal grid at the flux site in domain 4 . Tidal grids occupied about $4.4 \%$ of the total number of grids in domain 4 . The location of the flux site is indicated as the black dot in Fig. 3a. In the CNTL simulation, only land and water grids existed. Figures $3 b$ and $d$ show the horizontal distributions of land use types in the TIDE and CNTL simulations, respectively. The land use descriptions are given in Table 1. The tidal flat land use type in the tidal parameterization was set as barren, sparsely vegetated land. The grid land use types that were located in the tidal flats in the CNTL simulation are summarized in Table 1. Tidal grids were classified into two groups depending on the land use type in the CNTL simulation as either the land to tide (LT) group or the water to tide (WT) group. Water bodies accounted for about 38\% of the tidal grids in the CNTL simulation. Primary changes in the surface fluxes over the tidal flats between the TIDE and CNTL simulations occurred differently depending on whether the tidal grid corresponded to LT or WT grids and this is further examined in section 3.3. 

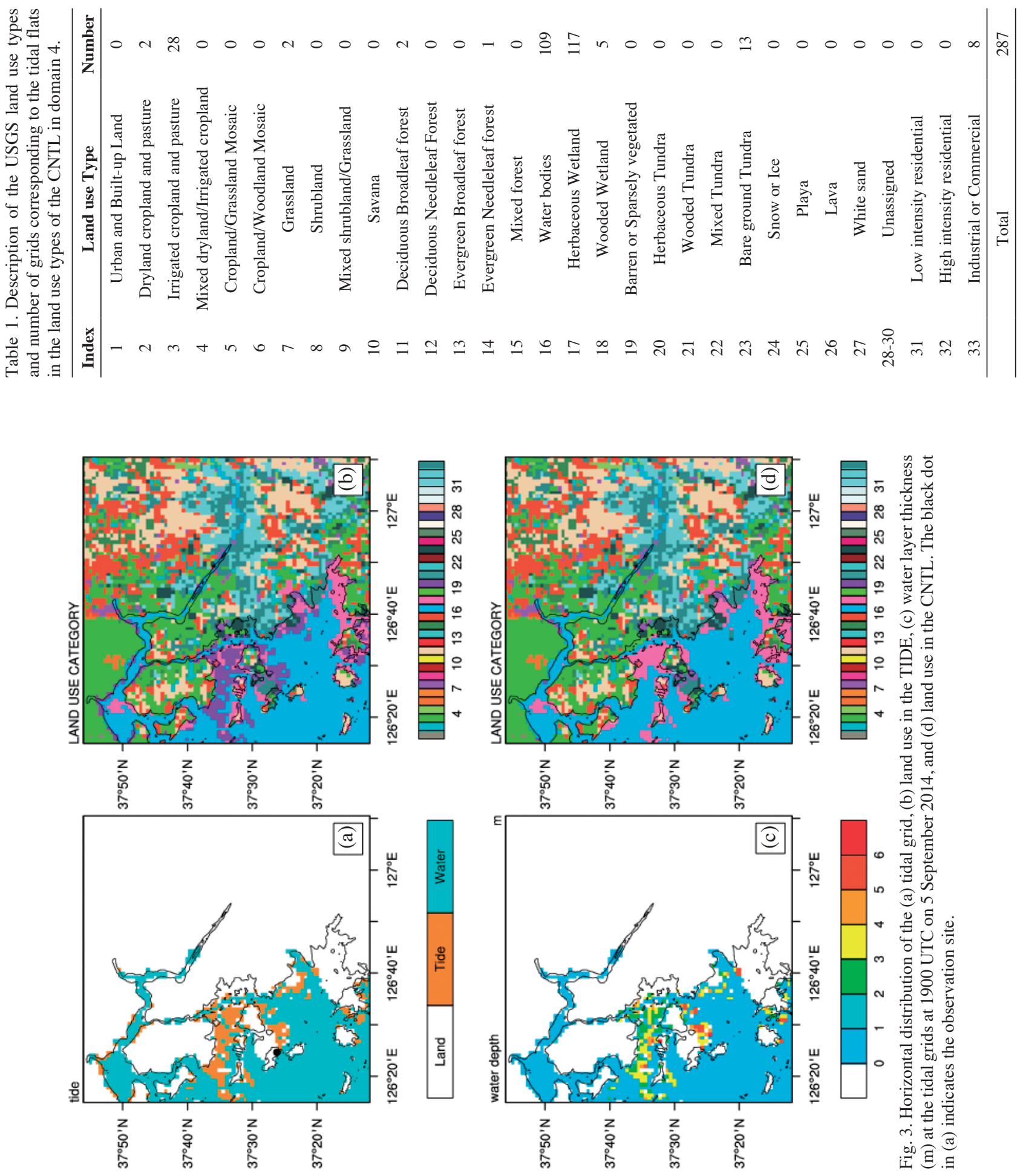
Figure $3 \mathrm{c}$ shows the horizontal distribution of the water layer thickness on the tidal grids at 1900 UTC during the inundation period. The water layer thickness ranged from zero to several meters, with a maximum of $6.3 \mathrm{~m}$. Figure 4 presents a comparison of the time series of the calculated water layer thickness near the flux site in the TIDE with the observations. The distance between the tidal grid and the flux site was about $1.4 \mathrm{~km}$. The diurnal variation of the calculated grid water layer thickness used in the TIDE was consistent with the observed water layer thickness at the flux site. However, the grid water layer thickness was greater and the grid inundation period was longer than the observations. The water layer thickness difference between observation and the calculated one was due to the difference in the location. The water layer thickness varied depending on the location (Fig. 3c). Also, the water layer thickness during the inundation period generally increased with increasing distance from the coast due to the sea facing slope of the coastal area. The measured water layer thickness was obtained at one point near the coast. Therefore, the magnitude of the averaged grid water layer thickness on the tidal flat was expected to be larger than the measured water layer thickness at the coast.

\subsection{Comparison of the Modelled Results with Observations}

In this section, we compared the two simulation results with observations obtained over the tidal flat. The land use type at the observation site was classified as "irrigated cropland and pasture" in the CNTL, and hence the observation site corresponded to the LT grid in the TIDE. The soil type at the observation site was silty clay loam in both simulations. Figure 5 presents a time series of the downward solar radiation, sensible and latent heat fluxes, and the friction velocity from the two simulations compared with the observations for selected three days. For the downward solar radiation, both simulations had nearly the same magnitude and well captured the observed features on 6 and 8 September. Some underestimation of downward solar radiation occurred in the afternoon on 7 September in both simulations due to the presence of clouds in the simulation.

The black bars in Fig. 5c indicate wind blowing from the land $\left(\mathrm{WD}<135^{\circ}\right.$ or $\mathrm{WD}>345^{\circ}$, where WD denotes the wind direction). Hereafter, we denote the wind from sea to land as the sea breeze and the wind from land to sea as the land breeze. A land breeze developed every night except for the evening of 8 September. Due to location of the flux tower, the tower provided good upwind fetches over the tidal flats only during westerly wind conditions (Lee et al. 2016). Therefore, to compare turbulent fluxes between the model and observation we focused on the westerly wind condition $\left(135^{\circ}<\mathrm{WD}<345^{\circ}\right)$.

During the daytime exposed conditions, the sensible heat fluxes were much greater in the CNTL than in the TIDE, and the magnitude of the turbulent fluxes in the TIDE agreed with the observations. The difference in sensible heat fluxes between the two simulations was due to differences in the roughness length and soil moisture contents between them. The roughness length $(0.1 \mathrm{~m})$ in the CNTL was 10 times greater than in the tidal flat $(0.01 \mathrm{~m})$. Table 2 displays the aerodynamic roughness length in two simulations and the estimated aerodynamic roughness length from observations using the Monin-Obukhov similarity during the exposed and inundation conditions for the sea and land breeze periods. For calculating the observation roughness length, we used data where the stability parameter $z / L$ ranged from -1.0 to 0.2 to exclude the extreme stability conditions. Here, $L$ is Obukhov length and $z$ is the height above the ground. During the sea breeze condition, the roughness length estimated from the observations over the exposed surface were close to the values used in the TIDE.

In the TIDE, the soil moisture was saturated during inundation and therefore, the soil moisture of the top soil layer $\left(0.464 \mathrm{~m}^{3} \mathrm{~m}^{-3}\right)$ was close to saturation during the exposed condition, while in the CNTL, the soil moisture of the top soil layer $\left(0.331 \mathrm{~m}^{3} \mathrm{~m}^{-3}\right)$ was about $71 \%$ of that in the TIDE. The latent heat flux magnitude in the TIDE was similar to that in the CNTL because the effect of the smaller roughness length cancels out the effects of the increased soil moisture. However, the increased soil moisture and decreased roughness length in the TIDE increases the ground heat flux and decreases the sensible heat flux compared to the CNTL. The ground heat flux was greater in the TIDE than in the CNTL (figure not shown).

The observations showed that the inundation significantly reduced both the sensible and latent heat daytime fluxes and this was well reproduced in the TIDE. Overestimation of latent heat flux was also noted during the nighttime inundation period, and this was due to the fact that the observed fluxes do not represents those over the tidal flat during the land breeze condition (Lee et al. 2016). During the land breeze period, the estimated aerodynamic roughness length from the observations were much greater than during the sea breeze period supporting that the observations did not represent those over the tidal flat (Table 2). The magnitude of the friction velocity was better simulated in the TIDE than in the CNTL (Fig. 5d).

Figure 6a shows a comparison of the air temperature at the measurement height $(\sim 10 \mathrm{~m})$ between the two simulations and the observations. The measurement height changed with water depth, ranging 7 to $10 \mathrm{~m}$. We estimated the air temperature at measurement height using logarithmic interpolation. The $2 \mathrm{~m}$ air temperature and the lowest-level air temperature (about $12.5 \mathrm{~m}$ ) were used in the interpolation. Although the sensible heat flux was much better simulated in the TIDE than in the CNTL, the air temperature did not exhibit large differences between the two simulations (Table 3 ). 


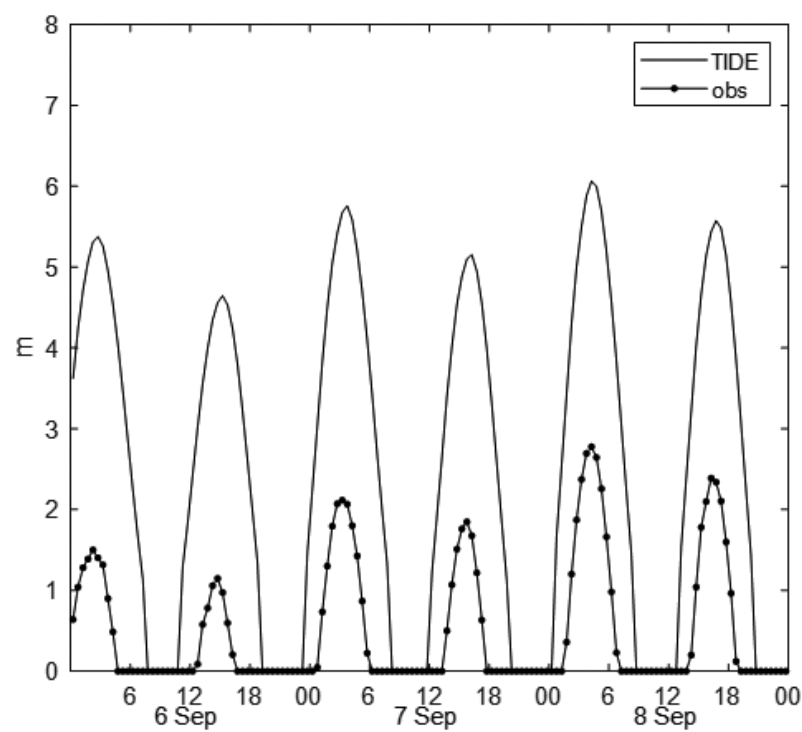

Fig. 4. Comparison of the calculated water layer thickness time series near flux site in the TIDE simulation with the observations.

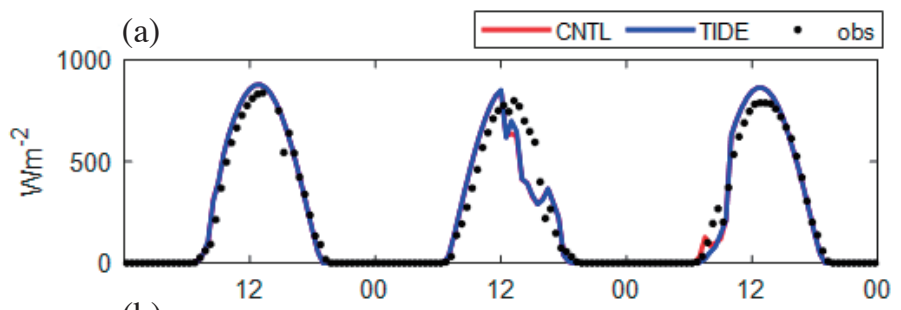

(b)

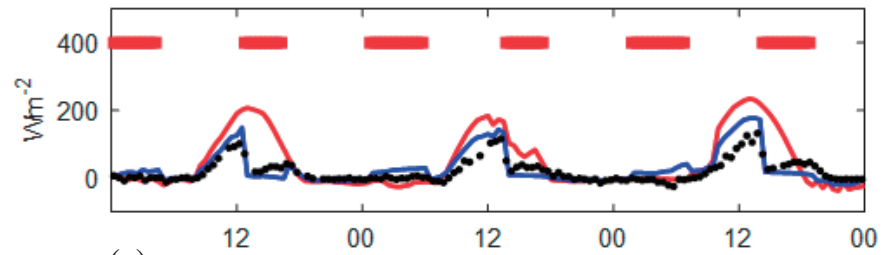

(c)

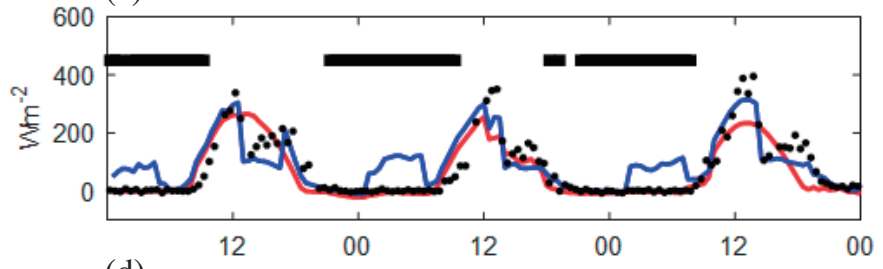

(d)

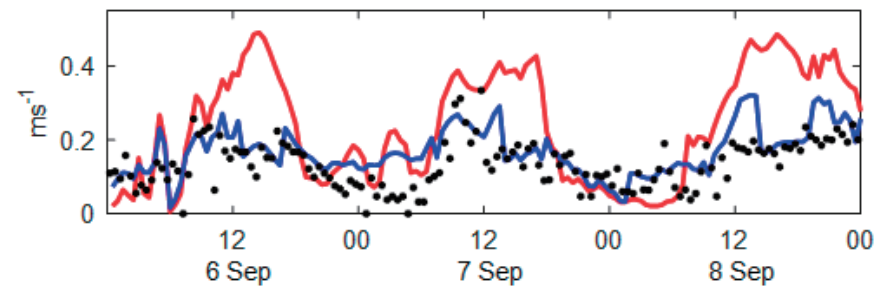

Fig. 5. Comparison of the (a) downward solar radiation, (b) sensible heat flux, (c) latent heat flux, and (d) friction velocity between the model simulations and observations. The red bars in (b) indicate the inundation period and the black bars in (c) indicate periods of land breeze. 
Table 2. Aerodynamic roughness length in the two simulations and observations at the flux site.

\begin{tabular}{c|cc|cc}
\hline & \multicolumn{2}{|c|}{ Sea breeze } & \multicolumn{2}{c}{ Land breeze } \\
\cline { 2 - 5 } & exposed & inundated & exposed & inundated \\
\hline Number of Obs & 26 & 17 & 13 & 8 \\
Observation (m) & 0.01 & 0.00096 & 0.52 & 0.21 \\
TIDE (m) & 0.01 & 0.00005 & 0.01 & 0.00002 \\
CNTL (m) & 0.1 & 0.1 & 0.1 & 0.1 \\
\hline
\end{tabular}
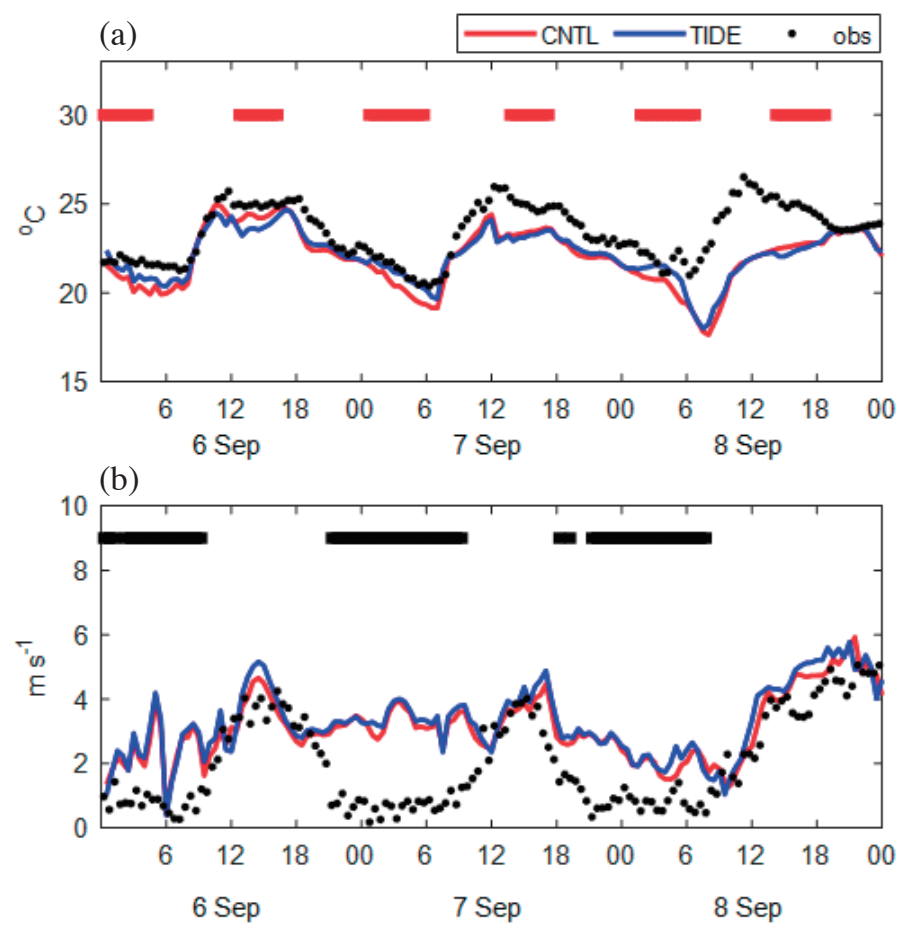

Fig. 6. Comparison of the (a) $10 \mathrm{~m}$ air temperature and (b) $10 \mathrm{~m}$ wind speed between the model simulations and observations. The red bars in (a) indicate the inundation period and the black bars in (b) indicate periods of land breeze.

Table 3. Root mean square errors for the air temperature and wind speeds at $10 \mathrm{~m}$ from the two simulations during the sea breeze condition for three selected days.

\begin{tabular}{c|cc|cc}
\hline & \multicolumn{2}{|c|}{ Daytime } & \multicolumn{2}{c}{ Nighttime } \\
\cline { 2 - 5 } & CNTL & TIDE & CNTL & TIDE \\
\hline Air temperature $(\mathrm{K})$ & 2.32 & 2.42 & 1.21 & 1.04 \\
Wind speed $\left(\mathrm{m} \mathrm{s}^{-1}\right)$ & 0.82 & 1.02 & 0.94 & 1.04 \\
\hline
\end{tabular}


The nighttime air temperature was slightly better simulated in the TIDE than in the CNTL (Table 3 and Fig. 6a). Both simulations showed increasing biases with simulation time. One possible reason for the underestimated daytime air temperature in both simulations is horizontal mixing. The tower is located at a heterogeneous site that consists of tidal flat, farmland, and forest (Fig. 2). During the daytime, air over the forest becomes heated due to larger absorptions of solar radiation and larger roughness lengths than over the tidal flat. Therefore, horizontal mixing of air could result in warmer air temperatures near the coast than over the middle of the tidal flat. For a $10 \mathrm{~m}$ wind speed, both simulations showed similar diurnal variations although the magnitude of the friction velocity was very different between the two simulations. The $10 \mathrm{~m}$ wind speed was slightly overestimated in the TIDE compared to the CNTL (Table 3 and Fig. 6b) during the daytime inundation period, due to the much smaller roughness length over the water than over the land (Table 2). However, impact of the roughness length on the wind speed is much less apparent than the impact of the roughness length on the friction velocity (Figs. $5 \mathrm{~d}$ and $6 \mathrm{~b}$ ). It is due to the fact that the forcing term of wind speed in momentum equation is the vertical convergence of turbulent momentum flux rather than the turbulent momentum flux itself.

\subsection{Tidal Parameterization Impact on the Simulated Meteorological Fields}

In order to investigate the impact of tidal parameterization on the meteorological fields, we selected four distinct cases consisting of $9 \mathrm{~h}$ simulation periods: inundation and exposed conditions during the nighttime, inundation and exposed conditions during the daytime. Table 4 displays the 9 $\mathrm{h}$ mean differences in the selected variables between the two simulations. The tidal grids with no water layer during the inundation period and with water layer during the exposed period were not included in the calculation of the mean differences in Table 4. The surface flux behaviors on the LT grids were similar to those reported in section 3.2. On the WT grids, the large surface flux differences were shown for the latent heat fluxes during the exposed condition.

Two sample t-tests were performed to evaluate the statistical significance of the difference for selected variables between the two simulations for the four distinct cases. Table 5 displays the number of grids that showed significant differences for the selected scalar variables at the $95 \%$ confidence level between the two simulations for the four cases. For the $10 \mathrm{~m}$ wind vector, the point with significant differences indicated that the $u$ or $v$ showed significant differences at the $95 \%$ confidence level. Except for the $10 \mathrm{~m}$ wind vector, the number of grids with significant differences was larger at night than during the daytime. One reason for this is that the sample variance of the scalar variables was larger during the daytime than during the nighttime. For the $10 \mathrm{~m}$ wind, the number of grids with significant differences was larger during the inundation period.

Figure 7 shows the horizontal distribution of the $9 \mathrm{~h}$ mean difference in the latent heat fluxes (TIDE-CNTL) between the two simulations. The black dots in Fig. 7 indicate the presence of significant latent heat flux differences between the two simulations. Significant flux differences are observed on the tidal grids or near the tidal grids. The latent heat flux increase occurred at the LT grids for the nighttime inundation conditions. This is because during the night both the water temperature and water availability at the LT grids in the TIDE were higher than those in the CNTL leading to an increased latent heat flux. A significant decrease in the latent heat flux was observed at the LT grids during the daytime inundation period and this is consistent with the observations noted in section 3.2. An increase in the latent heat flux was observed at the WT grids during the daytime exposed condition due to the higher surface temperature and increased surface roughness of the exposed tidal flat. Similar patterns were also noted for the sensible heat flux differences (Fig. 8). However, the difference in the nighttime sensible heat flux was much smaller than that of the latent heat flux. This is because most of the available energy was used for evaporation rather than the sensible heat flux over the water.

In order to examine the surface forcing of the tidal flats on the meteorological fields, we compared the air

Table 4. The $9 \mathrm{~h}$ mean difference (TIDE-CNTL) in the selected scalar variables between the TIDE and CNTL over the WT and LT grids for four distinct periods. $\lambda E$ : latent heat flux $\left(\mathrm{W} \mathrm{m}^{-2}\right) ; H$ : sensible heat flux $\left(\mathrm{W} \mathrm{m}^{-2}\right) ; T$ : air temperature at $2 \mathrm{~m}(\mathrm{~K})$; PBLH: planetary boundary layer height (m); WT: water to tide grid; LT: land to tide grid. The tide grids with no water layer during the inundation period and with a water layer during the exposed period were not included in the mean difference calculations.

\begin{tabular}{c|cc|cc|cc|cc}
\hline & \multicolumn{2}{|c|}{ Nighttime inundation } & \multicolumn{2}{|c|}{ Nighttime exposed } & \multicolumn{2}{c|}{ Daytime inundation } & \multicolumn{2}{c}{ Daytime exposed } \\
\cline { 2 - 9 } & WT & LT & WT & LT & WT & LT & WT & LT \\
\hline$\lambda E$ & 0.9 & 100.4 & -58.7 & 11.2 & 8.4 & -134.1 & 137.5 & 1.2 \\
$H$ & -1.7 & 30.0 & -14.4 & 7.5 & 1.0 & -126.6 & 64.4 & -45.8 \\
$T$ & 0.3 & 2.6 & -0.9 & 1.3 & -0.1 & -1.2 & 0.8 & -0.2 \\
PBLH & 15.5 & 16.1 & 74.0 & 15.6 & -9.1 & -195.1 & 187.0 & -23.9 \\
\hline
\end{tabular}


Table 5. The number of grids with significant differences at the $95 \%$ confidence level for the selected variables between two simulations for four distinct periods.

\begin{tabular}{c|cccc}
\hline Variables & $\begin{array}{c}\text { Nighttime } \\
\text { inundation }\end{array}$ & $\begin{array}{c}\text { Nighttime } \\
\text { exposed }\end{array}$ & $\begin{array}{c}\text { Daytime } \\
\text { Inundation }\end{array}$ & $\begin{array}{c}\text { Daytime } \\
\text { exposed }\end{array}$ \\
\hline Latent heat flux & 252 & 341 & 190 & 122 \\
Sensible heat flux & 294 & 316 & 191 & 244 \\
PBL height & 318 & 34 & 181 & 148 \\
$T$ at $2 \mathrm{~m}$ & 357 & 289 & 155 & 47 \\
$u$ or $v$ at $10 \mathrm{~m}$ & 167 & 17 & 197 & 24 \\
\hline
\end{tabular}
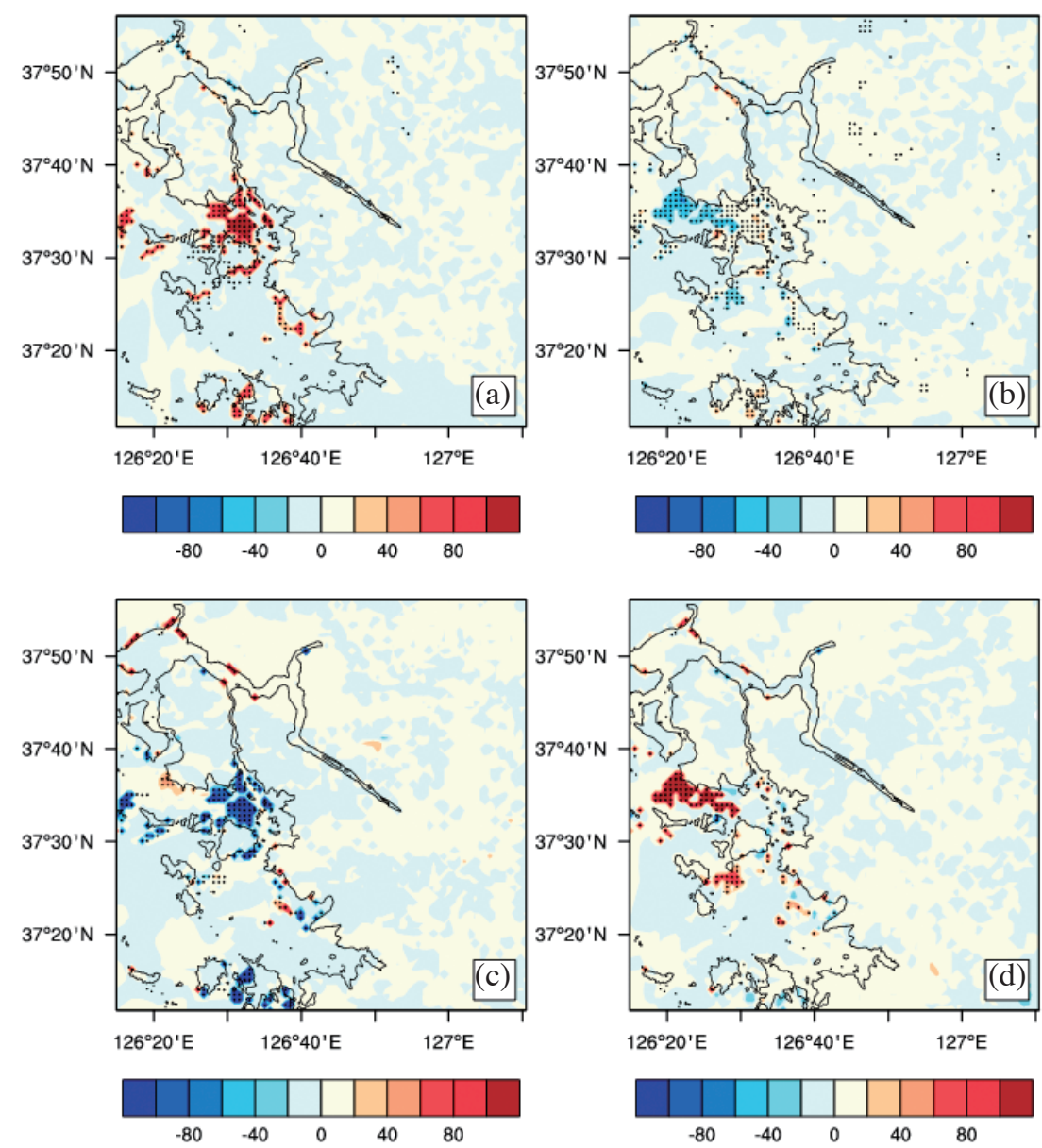

Fig. 7. Horizontal distribution of the $9 \mathrm{~h}$ mean differences in the simulated latent heat flux ( $\mathrm{W} \mathrm{m}^{-2}$ ) between the TIDE and CNTL during (a) nighttime inundation, (b) nighttime exposed, (c) daytime inundation, and (d) daytime exposed hours during the simulation period. The black dots in the figures indicate the presence of significant differences between the two simulations at the $95 \%$ confidence level. 

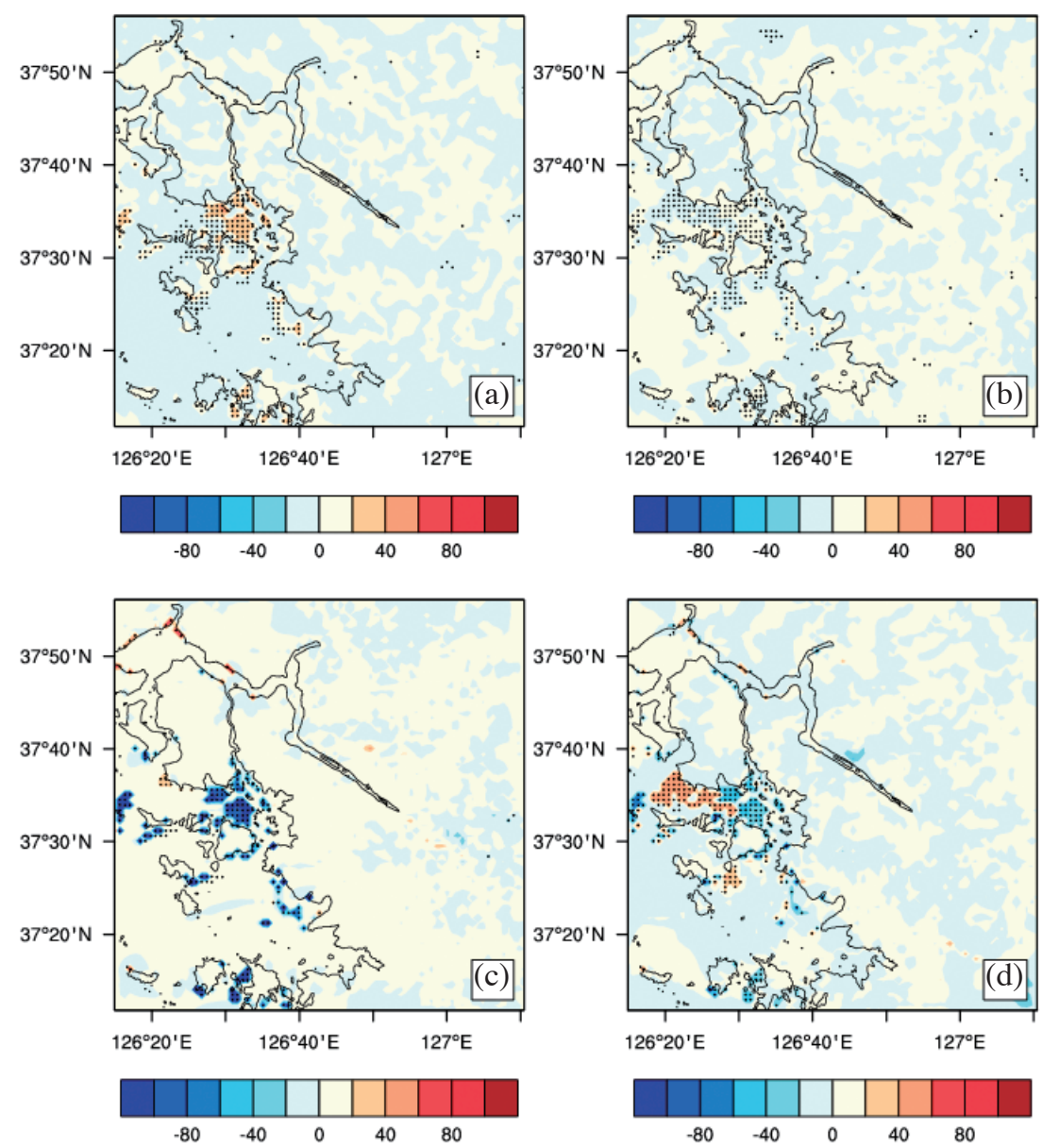

Fig. 8. Horizontal distribution of the $9 \mathrm{~h}$ mean differences in the simulated sensible heat flux ( $\mathrm{W} \mathrm{m}^{-2}$ ) between the TIDE and CNTL during (a) nighttime inundation, (b) nighttime exposed, (c) daytime inundation, and (d) daytime exposed hours during the simulation period. The black dots in the figures indicate the presence of significant differences between the two simulations at the $95 \%$ confidence level.

temperature at $2 \mathrm{~m}$, the planetary boundary layer height (PBLH), and the wind vectors at $10 \mathrm{~m}$ between the two simulations. Figure 9 shows the horizontal distribution of the $9 \mathrm{~h}$ mean differences in the air temperature at $2 \mathrm{~m}$ between the two simulations. The air temperature over tidal flats in the TIDE exhibited a consistent response to the sensible heat flux forcing, leading to warming at night and cooling during the day over the LT grids under the inundation conditions. Although the flux difference was larger during the daytime than at night, the air temperature differences over the LT grids between the two simulations exhibited a larger magnitude during the nighttime (Table 4). This is because during the night, the effect of surface forcing on the air temperature is confined near the surface due to weak turbulence, while during the daytime it extends vertically due to the larger PBLH (figure not shown).

The horizontal distribution of the mean difference in the PBLH between the two simulations is shown in Fig. 10. Although the number of grids with significant differences was largest during the nighttime inundation period, the magnitude of the PBLH difference was small and hence its impact on the variable vertical mixings were not expected to be large (Table 4). During the daytime, the PBLH differences between the two simulations was larger (Table 4 and Fig. 10c) than at night. Therefore, this implies that using the tidal parameterization could significantly impact the simulation of the air pollutant concentration over the tidal flats and the surrounding area during the daytime. During the nighttime exposed condition, an increase in the PBLH over the WT grid was noted although only a small number of grids showed significant differences. This is related to the use of different critical Richardson numbers between the over water in unstable conditions and the over land to detect the PBLH in the YSU PBL scheme. The critical Richardson number is a function of the roughness length over the water in unstable conditions, and is usually smaller than the critical Richardson number of 0.25 used over land, leading to a larger PBLH over land than over water during windy conditions.

Figure 11 shows the horizontal distribution of the $9 \mathrm{~h}$ mean wind vector at $10 \mathrm{~m}$ for the four cases. Land and sea breezes are shown for the nighttime inundation and daytime inundation periods, respectively. The exposed periods 

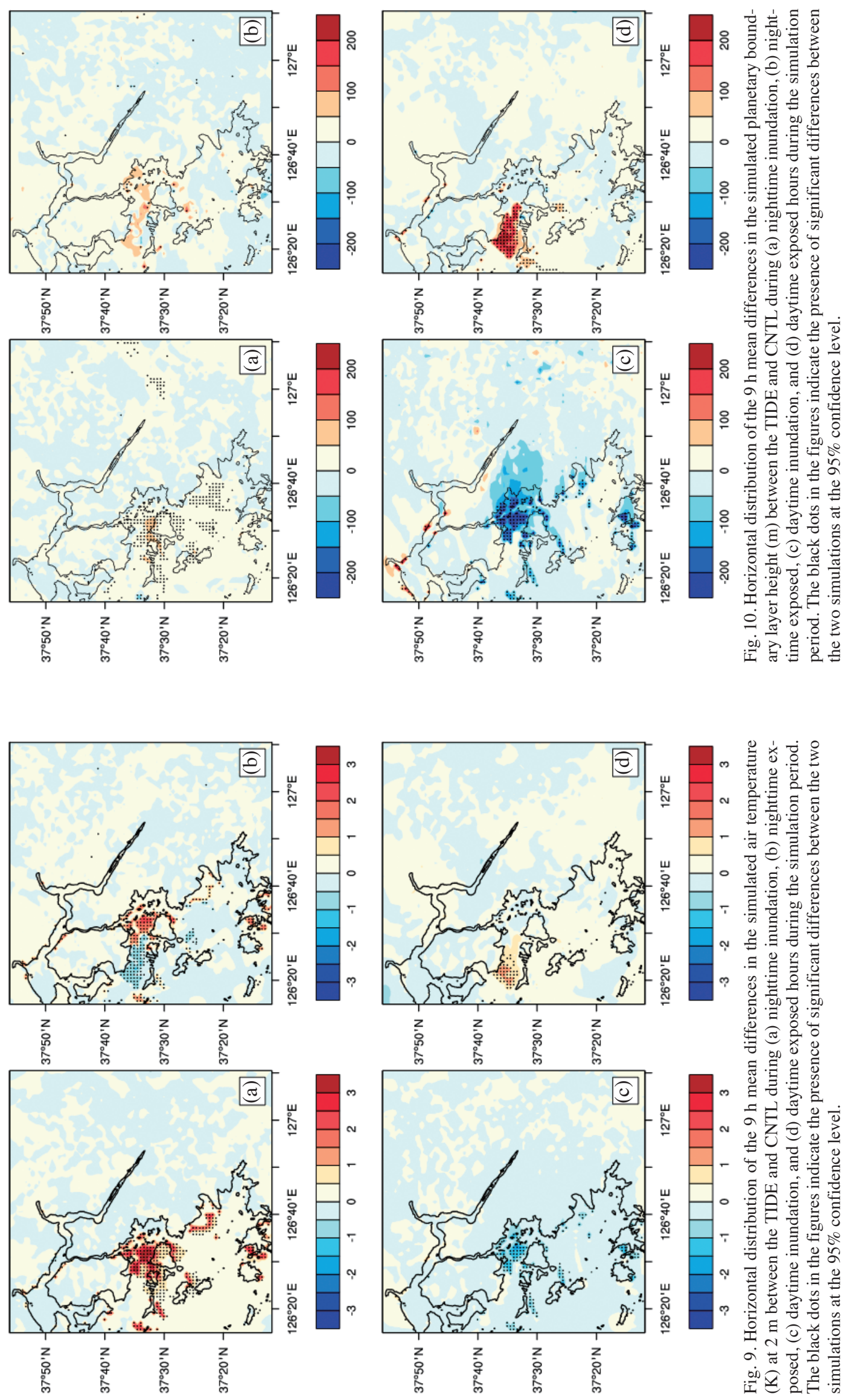

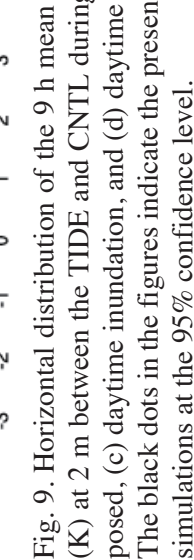




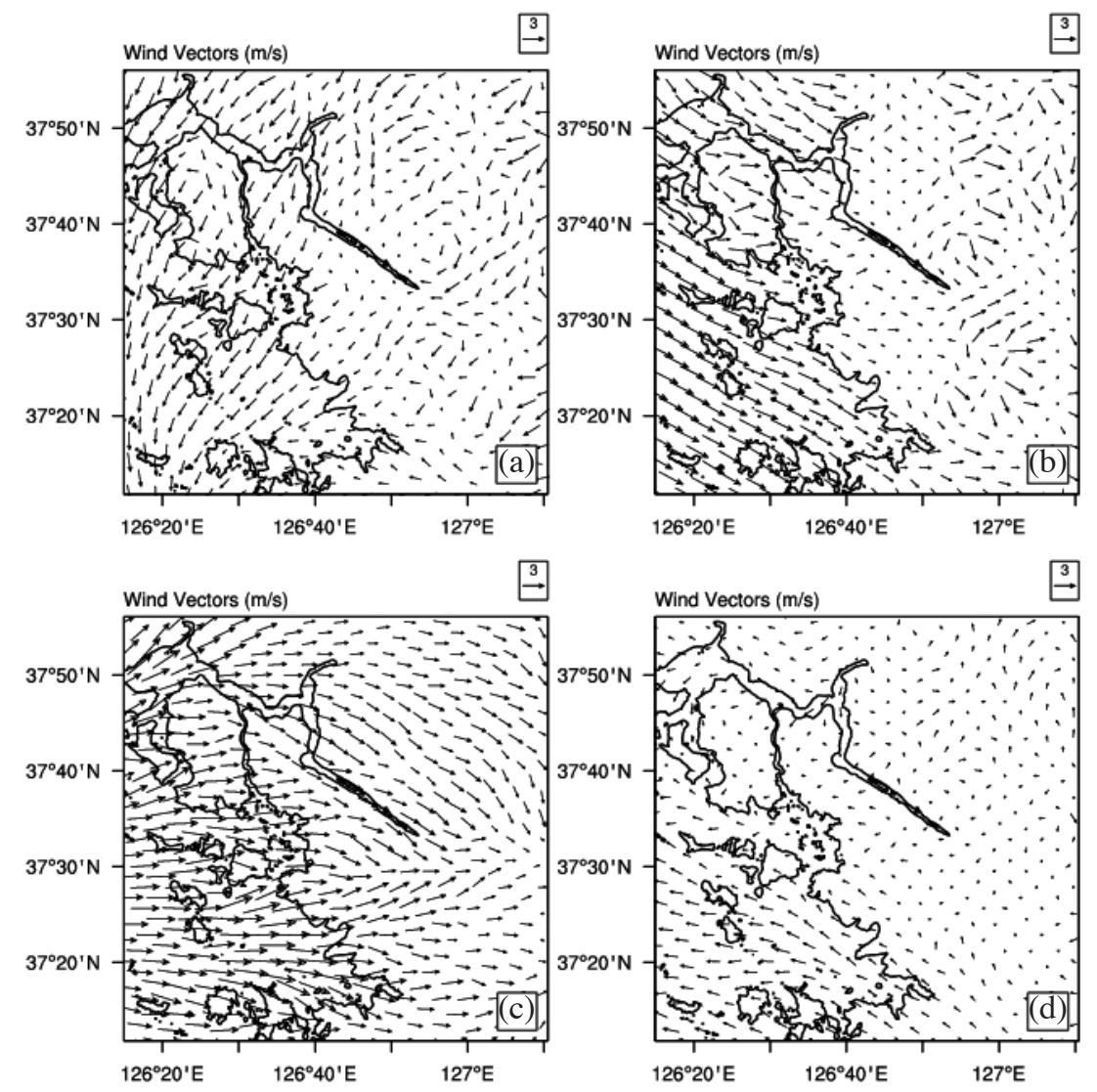

Fig. 11. Horizontal distribution of the $9 \mathrm{~h}$ mean wind vector at $10 \mathrm{~m}$ in the CNTL during (a) nighttime inundation, (b) nighttime exposed, (c) daytime inundation, and (d) daytime exposed hours during the simulation period.

include morning and evening transition periods (Fig. 4), and hence land and sea breezes are not clearly shown: during daytime exposed period, the weak southeasterly was shown over the sea, while during the nighttime exposed period, the strong northwesterly was shown over the sea with the weaker wind over land. Figure 12 shows the horizontal distribution of the $9 \mathrm{~h}$ mean wind vector differences at $10 \mathrm{~m}$ between the two simulations. The black dots indicate the presence of significant differences in the $u$ or $v$ component of the $10 \mathrm{~m}$ wind between the two simulations. We added colors to indicate the land cover changes between the TIDE and CNTL. For example, the pink color indicates water in the TIDE, but land in the CNTL. Significant difference in the $u$ or $v$ component between the two simulations are shown on the land-to-water grids. During the nighttime inundation condition, the land breeze was enhanced along the coast due to the boundary shift between the land and sea. During the daytime inundation condition, the enhanced sea breeze was not confined to the coast, but extends farther inland although significant changes are confined to the tidal flat and coastal areas. This is consistent with the finding of Kessler et al. (1985), who found that the effect of inundation on a well-developed sea breeze involves both a translation and intensification of the sea breeze front. During exposed conditions, only small number of grids showed significant wind changes (Table 5).

\section{SUMMARY AND CONCLUSIONS}

In this study, we implemented tidal parameterizations in the WRF model and examined the impact of tidal parameterization on the meteorological fields. Newly added inputs for the WRF model were gridded tidal data and time varying water layer thicknesses over the tidal flat. The gridded tidal data and water layer thickness data were produced using FVCOM. The tidal effect was considered only in the innermost domain with a $1 \mathrm{~km}$ horizontal resolution where the tidal flat was resolved. Two simulations were performed: a simulation without tidal effects (CNTL) and a simulation with tidal effects (TIDE).

We evaluated the implementation of the parameterization against the observations at single point over a tidal flat. Comparisons of the simulation results have been made with the flux measurements, air temperature, and wind speed at $10 \mathrm{~m}$ for three days with clear skies. The diurnal variation and magnitude of both the latent and sensible heat fluxes were well reproduced in the TIDE simulation. The air temperature was slightly better simulated in the TIDE than in 


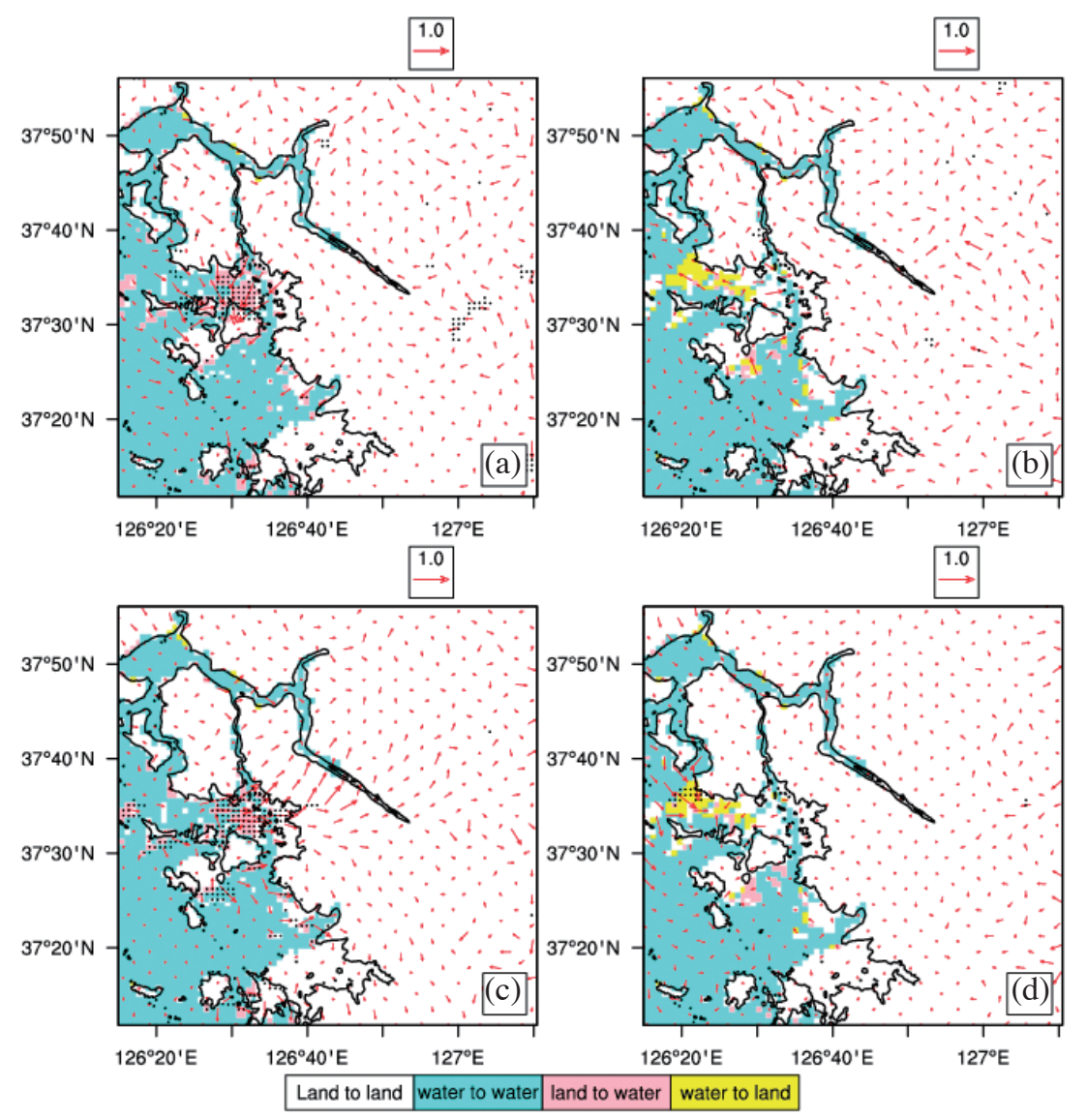

Fig. 12. Horizontal distribution of the $9 \mathrm{~h}$ mean differences in the simulated wind vector at $10 \mathrm{~m}$ between the TIDE and CNTL during (a) nighttime inundation, (b) nighttime exposed, (c) daytime inundation, and (d) daytime exposed hours during the simulation period. The black dots in the figures indicate the presence of significant differences in the $u$ or $v$ component between the two simulations at the $95 \%$ confidence level.

the CNTL only during the nighttime. However, the $10-\mathrm{m}$ wind speed was not better simulated in the TIDE compared to the CNTL. The mismatch between the observations and the TIDE simulation are partly due to location of the flux tower at the boundary of the tidal flat. During the daytime, horizontal mixing of the air between the tidal flat and the forest could result in warmer air temperatures and lower wind speeds. Despite the large differences in the surface fluxes between the two simulations, the difference in the $10-\mathrm{m}$ air temperatures and wind speeds between the two simulations was small.

The impact of the tidal parameterization on the meteorological fields was examined. The differences in the turbulent fluxes between the TIDE and CNTL simulations were examined for the four cases; (1) the nighttime inundation, (2) the nighttime exposed conditions, (3) the daytime inundation, and (4) the daytime exposed conditions. Two sample t-tests were performed to evaluate the statistical significances of difference for selected variables between the two simulations for the four distinct cases. During the inundation period, significant increases in the turbulent fluxes were exhibited during the nighttime and significant decreas- es in the turbulent fluxes were exhibited during the daytime on the LT grids. The 2-m air temperature over the tidal flats showed a consistent response to changes in the sensible heat fluxes, but the magnitude of air temperature changes were larger at night than during the daytime due to less vertical mixing during the night. The PBLH was significantly reduced over the tidal flats and near the inland area during the daytime inundation conditions and this could reduce the vertical dispersion of air pollutants near the coast. Further, the land and sea breezes along the coast were enhanced due to shifts in the boundary between the land and water in the TIDE simulation. During the daytime inundation conditions, enhanced sea breeze extended farther inland although significant changes in the scalar components were confined to the tidal flat and coastal areas.

We expect that applying the WRF model with tidal parameterizations would provide better meteorological fields over the coastal regions, and this could also contribute to improving the forecasting of air pollutant concentrations in coastal regions.

Acknowledgements This work was supported by Research 
and Development for the KMA Weather, Climate, and Earth system Services (NIMS-2016-3100). We thank two anonymous reviewers for their constructive comments.

\section{REFERENCES}

Charnock, H., 1955: Wind stress on a water surface. $Q$. J. R. Meteorol. Soc., 81, 639-640, doi: 10.1002/ qj.49708135027. [Link]

Chen, C., H. Liu, and R. C. Beardsley, 2003: An unstructured grid, finite-volume, three-dimensional, primitive equations ocean model: Application to coastal ocean and estuaries. J. Atmos. Ocean. Technol., 20, 159-186, doi: 10.1175/1520-0426(2003)020<0159:AUGFVT $>2$ .0.CO;2. [Link]

Chen, F. and J. Dudhia, 2001: Coupling an advanced land surface-hydrology model with the Penn State-NCAR MM5 modeling system. Part I: Model implementation and sensitivity. Mon. Weather Rev., 129, 569-585, doi: 10.1175/1520-0493(2001)129<0569:CAALSH>2.0. CO;2. [Link]

Crosman, E. T. and J. D. Horel, 2010: Sea and lake breezes: A review of numerical studies. Bound.-Layer Meteor., 137, 1-29, doi: 10.1007/s10546-010-9517-9. [Link]

De Meij, A. and J. F. Vinuesa, 2014: Impact of SRTM and Corine land cover data on meteorological parameters using WRF. Atmos. Res., 143, 351-370, doi: 10.1016/j. atmosres.2014.03.004. [Link]

Dudhia, J., 1989: Numerical study of convection observed during the winter monsoon experiment using a mesoscale two-dimensional model. J. Atmos. Sci., 46, 30773107, doi: 10.1175/1520-0469(1989)046<3077:NSOC OD $>2.0 . \mathrm{CO} ; 2$. [Link]

Harrison, S. J., 1985: Heat exchanges in muddy intertidal sediments: Chichester Harbour, West Sussex, England. Estuar. Coast. Shelf Sci., 20, 477-490, doi: 10.1016/0272-7714(85)90090-3. [Link]

Hong, S.-Y. and J. Dudhia, 2012: Next-generation numerical weather prediction: Bridging parameterization, explicit clouds, and large eddies. Bull. Amer. Meteorol. Soc., 93, ES6-ES9, doi: 10.1175/2011BAMS3224.1. [Link]

Hong, S.-Y., Y. Noh, and J. Dudhia, 2006: A new vertical diffusion package with an explicit treatment of entrainment processes. Mon. Weather Rev., 134, 2318-2341, doi: 10.1175/mwr3199.1. [Link]

Kain, J. S. and J. M. Fritsch, 1993: Convective parameterization for mesoscale models: The Kain-Fritsch scheme. In: Emanuel, K. A. and D. J. Raymond (Eds.), The Representation of Cumulus Convection in $\mathrm{Nu}-$ merical Models, American Meteorological Society,
Boston, MA, 165-170, doi: 10.1007/978-1-935704-133_16. [Link]

Kessler, R. C., D. Eppel, R. A. Pielke, and J. McQueen, 1985: A numerical study of the effects of a large sandbar upon sea breeze development. Archives for Meteorology, Geophysics, and Bioclimatology Series A, 34, 3-26, doi: 10.1007/bf02267392. [Link]

Lee, Y.-H., K.-D. Ahn, and Y. H. Lee, 2016: Parametrization of the tidal effect for use in the noah land-surface model: Development and validation. Bound.-Layer Meteor., 161, 561-574, doi: 10.1007/s10546-0160178-1. [Link]

Lu, R. and R. P. Turco, 1995: Air pollutant transport in a coastal environment-II. Three-dimensional simulations over Los Angeles basin. Atmos. Environ., 29, 1499-1518, doi: 10.1016/1352-2310(95)00015-Q. [Link]

Mlawer, E. J., S. J. Taubman, P. D. Brown, M. J. Iacono, and S. A. Clough, 1997: Radiative transfer for inhomogeneous atmospheres: RRTM, a validated correlated-k model for the longwave. J. Geophys. Res., 102, 1666316682, doi: 10.1029/97jd00237. [Link]

NIMR, 2014: Construction of Input Data for WRFUCM Using GIS and Its Operating Method, NIMRTN-2014-016, 47 pp.

Otte, T. L., A. Lacser, S. Dupont, and J. K. S. Ching, 2004: Implementation of an urban canopy parameterization in a mesoscale meteorological model. J. Appl. Meteorol., 43, 1648-1665, doi: 10.1175/jam2164.1. [Link]

Park, J.-Y. and M.-S. Suh, 2015: Improvement of MODIS land cover classification over the Asia-Oceania region. Kor. J. Rem. Sens., 31, 51-64, doi: 10.7780/ kjrs.2015.31.2.1. [Link]

Skamarock, W. C., J. B. Klemp, J. Dudhia, D. O. Gill, D. M. Barker, M. G. Duda, X.-Y. Huang, W. Wang, and J. G. Powers, 2008: A Description of the Advanced Research WRF Version 3, NCAR Technical Note, NCAR/TN-475+STR, National Center for Atmospheric Research, Boulder, Colorado, USA, 113 pp.

Smith, S. D., 1988: Coefficients for sea surface wind stress, heat flux, and wind profiles as a function of wind speed and temperature. J. Geophys. Res., 93, 15467-15472, doi: 10.1029/JC093iC12p15467. [Link]

Stull, R. B., 1988: An Introduction to Boundary Layer Meteorology, Springer Netherlands, 670 pp, doi: 10.1007/978-94-009-3027-8. [Link]

Tao, W.-K., J. Simpson, and M. McCumber, 1989: An icewater saturation adjustment. Mon. Weather Rev., 117, 231-235, doi: 10.1175/1520-0493(1989)117<0231:AIWSA $>2.0 . C O ; 2$. [Link] 